\title{
Evidencia molecular de Leptospira interrogans sensu stricto en Cavia porcellus (cuyes) destinados para el consumo humano en el municipio de Pasto, Nariño
}

\author{
Molecular evidence of Leptospira interrogans sensu stricto in Cavia porcellus (guinea pig) grown for human consumption \\ in Pasto, Nariño \\ Bibiana Benavides-Benavides ${ }^{*}$ orcid.org/0000-0002-5459-5172 \\ Hernán Darío Cisneros-López¹ orcid.org/0000-0001-9451-443X \\ Ronald Guillermo Peláez-Sánchez² orcid.org/0000-0002-2815-9844
}

1. Departamento de Salud Animal, Universidad de Nariño, Pasto, Colombia.

2. Grupo de investigación de Ciencias Básicas, Escuela de Graduados Universidad CES, Medellín, Colombia.

Benavides-Benavides B, Cisneros-López HD, Peláez-Sánchez RG. Evidencia molecular de Leptospira interrogans sensu stricto en Cavia porcellus (cuyes) destinados para el consumo humano en el municipio de Pasto, Nariño. Univ. Salud. 2022;24(1):55-64. DOI: https://doi.org/10.22267/rus.222401.258

\section{Resumen}

Introducción: La leptospirosis es una zoonosis emergente, endémica en Colombia, que afecta tanto animales domésticos como silvestres. Es considerada de riesgo laboral, ya que la transmisión al ser humano está asociada a la exposición con animales o ambientes infectados. En el departamento de Nariño, la producción de cuyes para el consumo humano se realiza en sistemas de crianza tradicionales que podrían favorecer la infección por Leptospira interrogans en esta especie. Objetivo: Detectar molecularmente la infección natural por especies patógenas del género Leptospira en cuyes que son destinados para el consumo humano en el municipio de Pasto. Materiales y métodos: Se tomaron 270 muestras de tejido renal en cuyes sacrificados en dos mataderos. Las muestras fueron analizadas mediante Reacción en Cadena de la Polimerasa (PCR) convencional y coloración diferencial de Warthin Starry (W-S). Resultados: En la evaluación de las 270 muestras, 4 (1,5\%) fueron positivas para PCR y una de las muestras demostró la presencia de Leptospira bajo tinción W-S. Conclusiones: Mediante el uso de técnicas moleculares se evidenció L. interrogans en el tejido renal de Cavia porcellus. La circulación del patógeno en esta población representa un riesgo de infección para humanos y animales domésticos en contacto con estos sistemas productivos.

Palabras clave: Cavia porcellus; leptospirosis; zoonosis. (Fuente: DeCS, Bireme).

\begin{abstract}
Introduction: Leptospirosis is an emerging zoonosis that is endemic in Colombia and affects both domestic and wild animals. It is considered an occupational risk since human transmission is associated with exposure to infected animals or environments. In the department of Nariño, the production of guinea pigs for human consumption applies traditional rearing systems that could cause animals to get infected with Leptosipira interrogans. Objective: To molecularly identify natural infection by pathogenic species of the genus Leptospira in guinea pigs used for human consumption in the municipality of Pasto (Colombia). Materials and methods: 270 kidney tissue samples were taken from guinea pigs slaughtered in two facilities. Samples were analyzed through conventional polymerase chain reaction (PCR) and Warthin Starry (W-S) differential staining. Results: While 4 (1.5\%) out of the 270 samples were categorized as positive using PCR, only 1 sample showed the presence of Leptospira through W-S staining. Conclusions: Molecular techniques were useful to identify L. interrogans in kidney tissue of Cavia porcellus. Dissemination of this pathogen within this population represents an infection risk for humans and domestic animals that are in close proximity to these productive systems.
\end{abstract}

Keywords: Cavia porcellus; leptospirosis; zoonoses. (Source: DeCS, Bireme).

\footnotetext{
*Autor de correspondencia Bibiana Benavides Benavides e-mail: bbenavides@udenar.edu.co
} 


\section{Introducción}

El departamento de Nariño es el principal productor de cuyes en Colombia con una participación del 91,4\% a nivel nacional( 1 ), donde Pasto es el municipio con mayor producción (50,4\%), seguido de los municipios de Ipiales y el Tambo(2). La crianza de cuyes ocupa un renglón importante en la economía rural de la región y es una práctica cultural ligada a sus costumbres que proporciona seguridad alimentaria y una fuente de ingresos a la población rural(3). Los sistemas de crianza cuyícolas, en su mayoría de tipo familiar, se caracterizan por la ausencia de un adecuado control sanitario, desconocimiento de las medidas y prácticas de bioseguridad, y sin técnicas apropiadas para diagnosticar problemas sanitarios(4).

La leptospirosis es una zoonosis emergente, prevalente en los países tropicales, causada por bacterias patógenas del género Leptospira(5), actualmente se conocen 65 especies clasificadas como saprofitas (subgrupos S1 y S2) y patógenas (subgrupos P1 y P2), a este último grupo pertenece la especie Leptospira interrogans, la que comúnmente genera la enfermedad en animales y en el humano(6). La leptospirosis está asociada con la exposición a animales, en especial roedores $y$ animales domésticos(7,8). Leptospira ingresa al sistema sanguíneo del hospedador, se multiplica y se localiza principalmente en los riñones(7). Los roedores son la principal fuente de infección porque al ser un hospedador de mantenimiento no presentan signos clínicos, pero eliminan un alto nivel de bacterias en la orina, contaminando el agua y el suelo, por lo que tienen un rol relevante dentro de la cadena epidemiológica de la enfermedad $(9,10)$.

En los humanos, la infección puede ser transmitida por contacto directo con animales infectados o indirectamente con el ambiente contaminado(11). La bacteria ingresa a través de microlesiones de la piel o a través de la mucosa intacta(12). Por esta razón, es considerada importante para la salud pública, ya que la mayoría de los casos en humanos responden a una exposición ocupacional (agricultor, productor, veterinario, operador de planta de beneficio), factores culturales (cría de animales, tenencia de mascotas), circunstancias socioeconómicas (saneamiento, pobreza) e inadecuada disposición de residuos ${ }^{(13,14) \text {. }}$
Por la importancia de los sistemas de crianza tradicional de los cuyes en Nariño y debido a las condiciones ambientales asociadas a su producción, se planteó detectar la infección natural por especies patógenas del género Leptospira en cuyes que son destinados para el consumo humano en el municipio de Pasto.

\section{Materiales y métodos}

\section{Lugar de estudio}

Las muestras de tejido renal se obtuvieron en dos mataderos de cuyes ubicados en los corregimientos de Catambuco y Genoy, al sur $\left(1^{\circ} 09^{\prime} 58,5^{\prime \prime} \mathrm{N}\right.$ $\left.77^{\circ} 17^{\prime} 57,6^{\prime \prime}\right)$ y nororiente $\left(1^{\circ} 16^{\prime} 00,7^{\prime \prime} \mathrm{N}\right.$ $77^{\circ} 20^{\prime} 03,5^{\prime \prime W}$ ) del municipio de Pasto. En estos establecimientos se sacrifican animales destinados para el consumo que provienen de sistemas de producción familiar ubicados en los municipios Pasto y El Tambo.

\section{Población y muestra}

En el proceso de sacrificio no se lleva ningún tipo de registro y el número de animales sacrificados responde a la demanda del producto, por lo tanto, el tamaño de la población es desconocido. Para efectos de este estudio la población está representada por el tejido renal de cuyes sacrificados para consumo humano en el municipio de Pasto.

Para definir el tamaño de muestra se usó el programa WinEpi® ${ }^{\odot}$ 2006, en el componente de detección de enfermedad o infección en una población de tamaño desconocido, se consideró un nivel de confianza de $90 \%$ y una prevalencia mínima esperada de $1 \%$. Se obtuvo un tamaño de muestra inicial de 230 individuos y se adicionaron 40 en caso de pérdida o deterioro de las muestras y se trabajó con un total de 270 animales. El muestreo se realizó por conveniencia en dos mataderos que permitieron el ingreso de los investigadores.

\section{Recolección de muestras}

La recolección de las 270 muestras se realizó en 4 visitas a cada establecimiento. Las muestras de tejido renal se obtuvieron de animales clínicamente sanos en el momento del sacrificio. Los riñones se recolectaron en el momento del eviscerado y se almacenaron en recipientes plásticos herméticos con formol bufferado al $10 \%$ y en bolsas plásticas estériles de cierre hermético con $5 \mathrm{ml}$ de solución buffer fosfato. Las muestras fueron enumeradas para 
garantizar la trazabilidad y se mantuvieron refrigeradas hasta su procesamiento.

\section{Diagnóstico por PCR}

Los tejidos almacenados en solución buffer fosfato fueron procesados para determinar la presencia del agente mediante Reacción en Cadena de la Polimersa (PCR) convencional. El ADN fue extraído a partir de $100 \mathrm{mg}$ de tejido renal. La extracción de ADN fue realizada utilizando el kit Wizard (Promega®. USA) de acuerdo con las instrucciones de manufactura. Todos los experimentos posteriores a la PCR fueron realizados con una concentración final de $20 \mathrm{ng}$ de ADN. La concentración y pureza fueron determinadas mediante Nanodrop, mientras que la integridad fue evaluada mediante geles de agarosa al 1\%.

Se amplificó Un fragmento de 317 pares de bases del gen ribosomal 16S usando los oligonucleótidos 16SF (GGCGCGTCTTAAACATGCAAG) y 16SR (GAGCAAGATTCTTAACTGCTGCC) ${ }^{(15,16) . \quad \text { La }}$ concentración de reactivos utilizada para la estandarización de la PCR fue la siguiente: Oligonucleótidos $(0,4 \mu \mathrm{M})$, dNTPs $(0,2 \mathrm{mM})$, buffer (1X), $\quad \mathrm{MgCl} 2 \quad(1,5 \mathrm{mM}), \quad \mathrm{Taq}$ polimerasa (1 unidad/reacción) y ADN (20 ng/ $\mu \mathrm{l})$, el volumen final para cada reacción fue de $25 \mu$ l. La PCR fue realizada en un termociclador Perkin Elmer 9700, el perfil térmico utilizado fue: un ciclo de desnaturalización inicial a $94^{\circ} \mathrm{C}$ por 5 minutos, seguido por 35 ciclos a $94{ }^{\circ} \mathrm{C}$ por 45 segundos, $64^{\circ} \mathrm{C}$ por 1 minuto, $72^{\circ} \mathrm{C}$ por 2 minutos y un ciclo de extensión final a $72{ }^{\circ} \mathrm{C}$ por 5 minutos.

Los productos de la PCR se visualizaron mediante electroforesis en geles de agarosa al 1,5\% teñidos con SYBR safe (Invitrogen, Carlsbad, CA) y se visualizaron con una cámara Epichemi. Las muestras positivas a PCR del gen ribosomal 16S se purificaron utilizando el kit Gel Extraction Kit (Qiagen ${ }^{\circledR}$ ). La concentración y la pureza se determinaron mediante Nanodrop, mientras que la integridad se evaluó mediante electroforesis en gel de agarosa al 1\%.

\section{Secuenciación de los amplificados}

Un fragmento de 317 pares de bases del gen ribosomal $16 \mathrm{~S}$ para cada muestra positiva fue enviado a secuenciar a la compañía Macrogen ${ }^{\circledR}$ Korean. Para cada muestra, tanto la secuencia directa como la inversa se utilizaron para generar una secuencia consenso utilizando el programa bioinformático MEGA-X (Análisis de Genética Evolutiva Molecular).

\section{Identificación de especies mediante análisis filogenético}

El gen ribosomal $16 \mathrm{~S}$ de 65 especies del género Leptospira fue utilizado como secuencias de referencia. Estas secuencias y aquellas obtenidas de las cuatro muestras positivas de cuyes fueron alineadas haciendo uso del programa bioinformático MEGA-X. El análisis filogenético fue realizado en MEGA-X, utilizando el método Neighbor-Joining con 1000 réplicas de Bootstrap(17). El árbol se dibujó a escala, con la longitud de las ramas en las mismas unidades que las distancias evolutivas empleadas para inferir el árbol filogenético. Las distancias evolutivas fueron computarizadas con el método paramétrico Kimura-2(18). Los análisis evolutivos se realizaron en MEGA-X(19).

\section{Coloración diferencial Warthin Starry}

El tejido renal de los 4 Cavia porcellus positivos a PCR previamente fijados en formol fueron sometidos a la técnica de inclusión en bloques de parafina y se generaron láminas delgadas a través de cortes generados por un micrótomo mediante el sistema de preparación de muestras histológicas (HistoStar ${ }^{\circledR}$ Thermo Scientific, USA). Posteriormente, se realizó la fijación de las láminas histológicas en placas de vidrio. Dichas láminas se utilizaron para realizar la coloración diferencial Warthin Starry (W-S), según el protocolo de las Fuerzas Armadas de Estados Unidos(20).

\section{Evaluación microscópica}

Las placas teñidas con la coloración diferencial de W$\mathrm{S}$ se evaluaron con un microscopio de luz óptico (Zeiss $^{\circledR}$ Primo Star, Alemannia) para detectar estructuras helicoidales compatibles con la morfología de espiroquetas en los túbulos renales de los cuyes.

\section{Análisis de los datos}

Se construyó una base de datos en el programa Microsoft ${ }^{\circledR}$ Excel 2010. Se registró la información de cada muestra, que incluía el código del animal, fecha de toma de la muestra, el lugar del muestreo y los resultados obtenidos PCR y tinción W-S.

Por la característica cualitativa de los datos obtenidos se analizaron mediante estadística descriptiva. Se estimó la proporción y su intervalo de confianza de los animales positivos a L. interrogans sensu stricto, para cada prueba diagnóstica y se determinó la correlación entre las dos pruebas. No se estableció la asociación de las muestras positivas con el lugar de 
procedencia porque este último corresponde a la ubicación del matadero.

\section{Consideraciones éticas}

El estudio fue aprobado por el Comité de Ética para el uso de animales vivos en experimentos e investigación de la Universidad de Nariño, el $1^{\circ}$ de abril de 2013.

\section{Resultados}

Se recolectaron 270 muestras de tejido renal en dos mataderos del municipio de Pasto, de las cuales 123 (46\%) corresponden al matadero del corregimiento de Genoy y 147 (54\%) del corregimiento de Catambuco. Los animales provenían de diferentes granjas familiares, y no fue posible establecer el origen de cada lote de animales sacrificados durante la toma de muestras.

El total de las muestras de tejido renal $(n=270)$ fueron evaluadas por PCR convencional, de las cuales cuatro muestras fueron positivas (Figura 1) y confirmadas como L. interrogans sensu stricto, por secuenciación y análisis filogenético. Al analizarlas con Tinción W-S, fue posible detectar estructuras similares a espiroquetas en una sola muestra (Figura 2). El diagnóstico positivo mediante dos métodos de detección diferentes corrobora la presencia de Leptospira en el tejido renal de los cuyes analizados. Los resultados obtenidos por cada una de las técnicas diagnósticas se describen en la Tabla 1.

Las 4 muestras positivas a Lepstospira mediante amplificación del gen ribosomal 16S mediante PCR, fueron secuenciadas en ambos sentidos y se construyó una secuencia consenso para cada una de ellas. Las secuencias de las cuatro muestras positivas fueron alineadas con las 65 especies de referencia del género Leptospira, se identificó que las cuatro estuvieron genéticamente relacionadas con la especie Leptospira interrogans con un soporte de rama entre (79-99\%) (Figura 3). Las secuencias de los animales positivos se sometieron a la base de datos del GenBank bajo los siguientes códigos: MZ749640 (cuy 1), MZ749639 (cuy 2), MZ749638 (cuy 3) y MZ749637 (cuy 4).

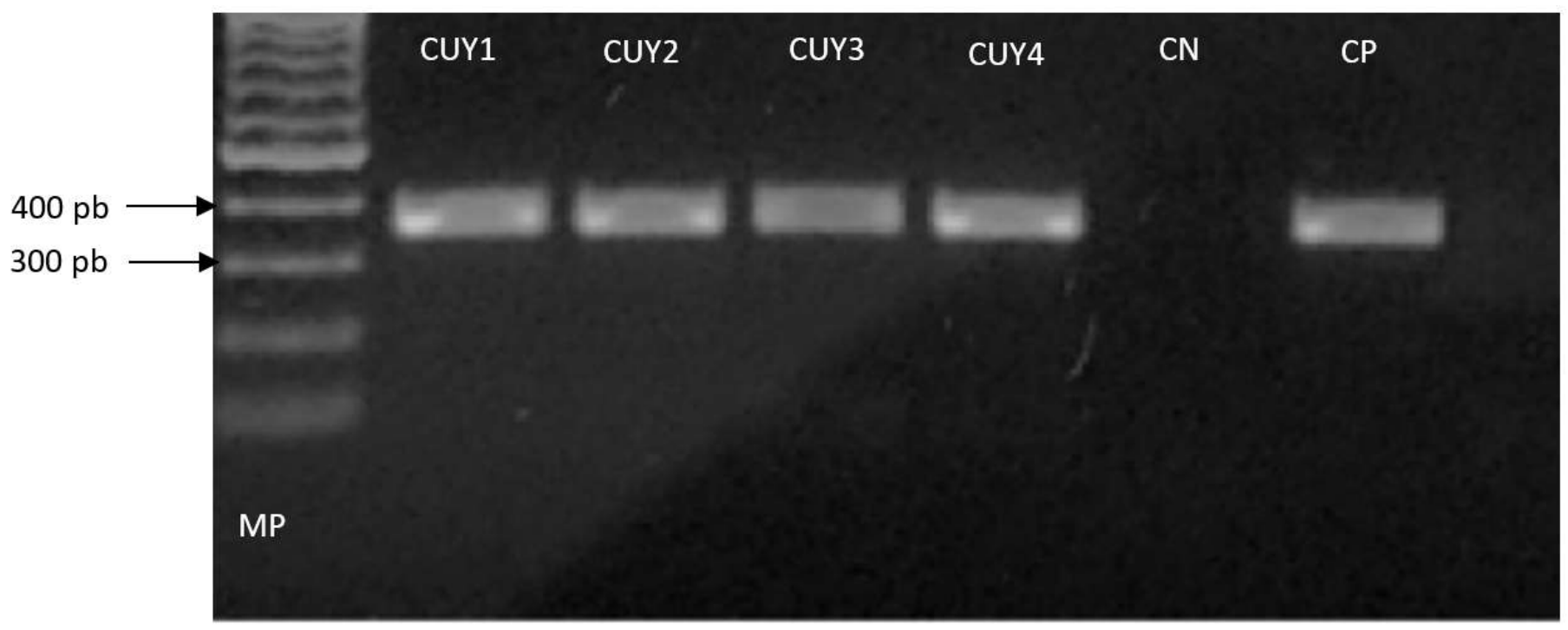

Figura 1. Detección molecular de Leptospira a partir de riñones de Cavia porcellus. Se muestra un gel de agarosa con los productos de amplificación de 4 cuyes infectados con Leptospira. La banda corresponde a un fragmento del gen ribosomal 16S (317 pares de bases). Se utilizó marcador de peso molecular de 100 pares de bases (las bandas de 300 y 400 pares de bases se indican con flechas negras). Adicionalmente, se utilizó un control positivo (CP-Leptospira interrogans) y un control negativo (CN- reactivos de PCR sin ADN) en todas las reacciones. 


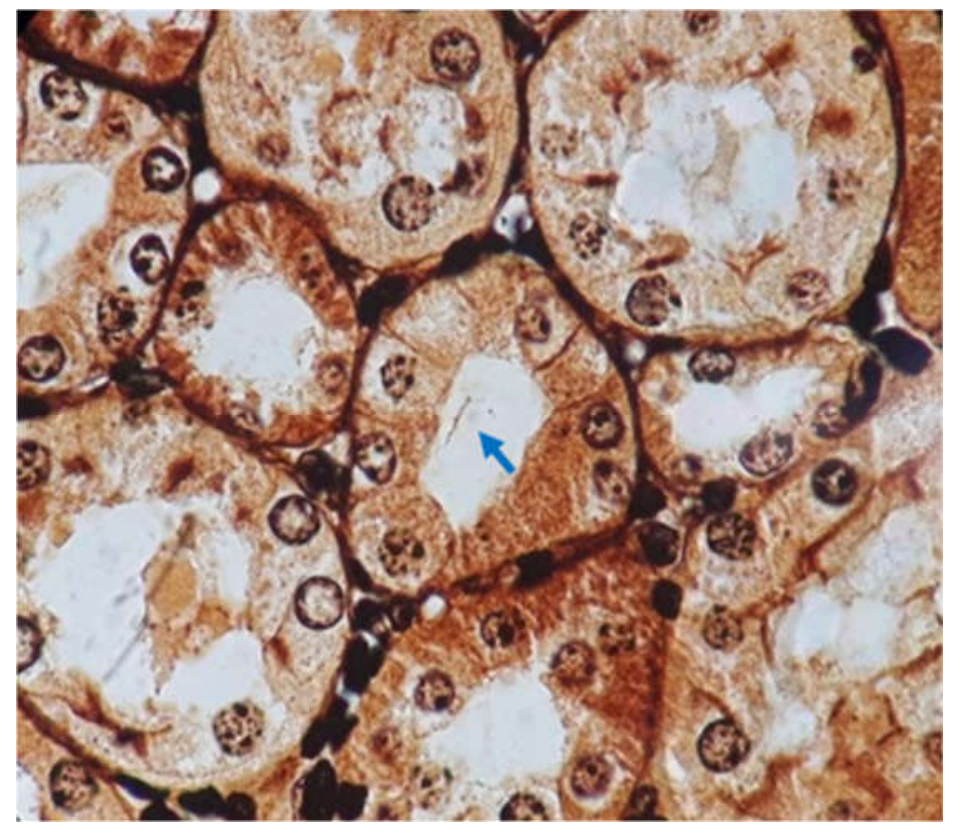

Figura 2. Tinción W-S en riñón de Cavia porcellus positivo a Leptospira en prueba de PCR. La flecha señala presencia de estructuras helicoidales compatibles con Leptospira en el lumen del túbulo contorneado (aumento de 100x) de una muestra de riñón proveniente de Cavia porcellus.

Tabla 1. Proporción de cuyes positivos a L. interrogans diagnosticados mediante PCR y tinción W-S en el municipio de Pasto

\begin{tabular}{lccccr}
\hline Prueba diagnóstica & Muestras analizadas & $\begin{array}{c}\text { Muestras } \\
\text { positivas }\end{array}$ & $\begin{array}{c}\text { Proporción de muestras } \\
\text { positivas (\%) }\end{array}$ & $\begin{array}{c}\text { Intervalos de confianza } \\
\text { (95\%) }\end{array}$ \\
\hline PCR convencional & 270 & 4 & $1,5 \%$ & $0,58-3,75$ \\
\hline Tinción W-S & 4 & 1 & $25 \%$ & $4,5-69,9$ \\
\hline
\end{tabular}

\section{Discusión}

Este estudio es el primer reporte de infección natural por Leptospira interrogans en cuyes (Cavia porcellus) en el municipio de Pasto. Se logró detectar la presencia de Leptospira en muestras de riñón mediante dos métodos de detección totalmente diferentes (PCR convencional e histopatología), por lo cual se corrobora la infección natural de Cavia porcellus. De 270 muestras de tejido renal analizadas, cuatro fueron confirmadas por PCR y una por PCR y tinción W-S. Se debe destacar que la tinción W-S fue menos eficiente en detectar la presencia de Leptospira en riñones de Cavia porcellus que la PCR convencional. Estos resultados son congruentes con diversas investigaciones en las cuales se resalta que la PCR tiene una mayor sensibilidad en el diagnóstico de la Leptospirosis que las pruebas histopatológicas(21). Sin embargo, se sugiere que la mejor herramienta para el diagnóstico de la leptospirosis animal es realmente una combinación entre las pruebas serológicas, moleculares y tinciones histopatológicas, debido a que dicha combinación aumenta la sensibilidad $y$ especificidad del diagnóstico.

Adicionalmente, esta combinación brinda a los investigadores la posibilidad de detectar un mayor número de animales infectados, la capacidad de medir el contacto previo de los animales con la bacteria mediante pruebas serológicas, detectar la infección de animales a partir de diferentes muestras de tejidos y fluidos mediante PCR y evaluar los daños ocasionados por la bacteria en los diferentes órganos mediante tinciones histopatológicas(21). Por lo tanto, los hallazgos de este trabajo se convierten en la base para desarrollar estudios que permitan esclarecer el rol de la especie Cavia porcellus en la epidemiología de la leptospirosis en el sur de Colombia. 


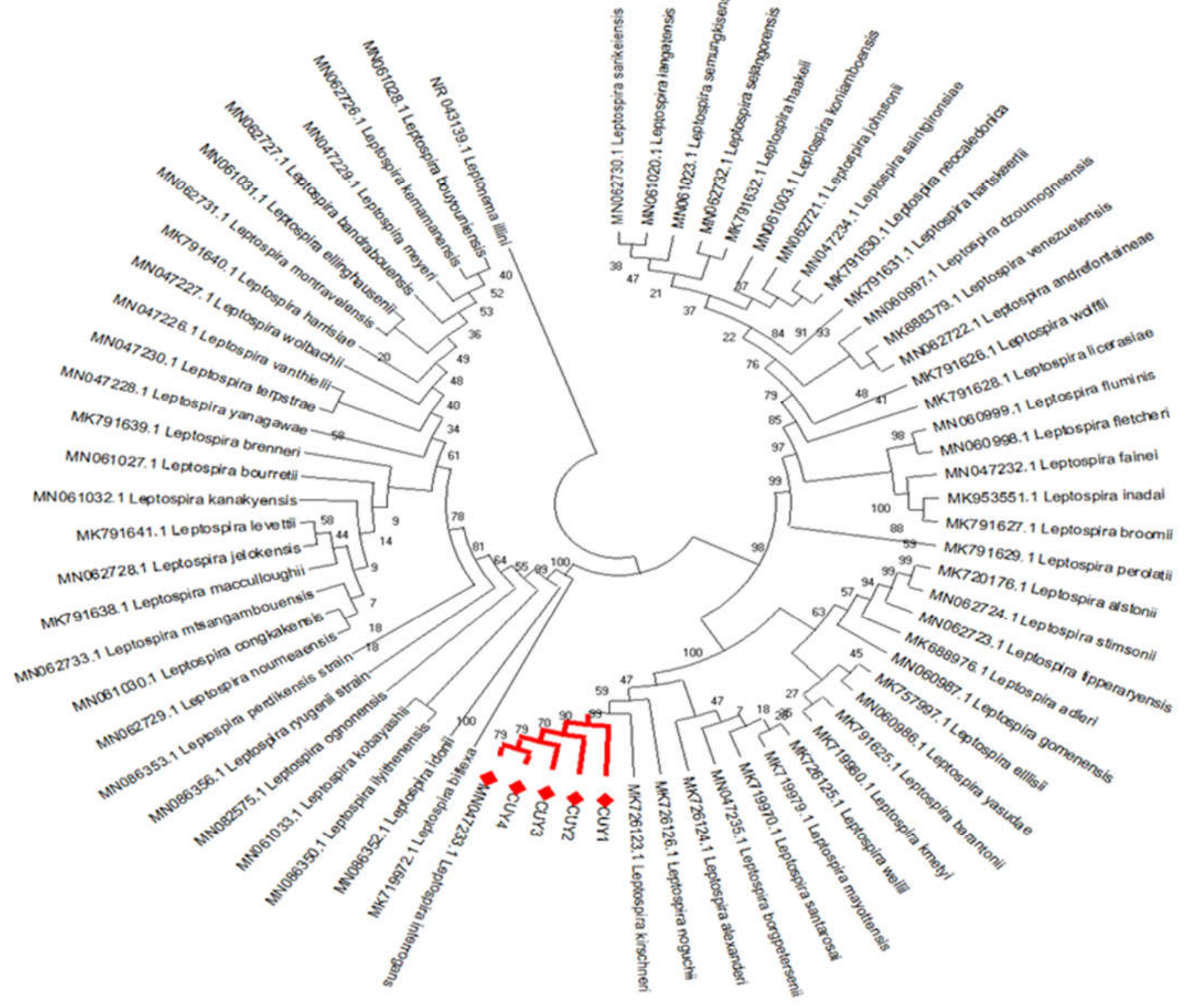

Figura 3. Identificación molecular de especies de Leptospira que infectan Cavia porcellus mediante análisis filogenético del gen ribosómico 16S. Se muestra la reconstrucción filogenética del gen ribosomal 16S del género Leptospira. Los diamantes rojos representan los cuyes infectados con Leptospira. La especie identificada en los 4 cuyes positivos fue Leptospira interrogans.

La mayoría de los reportes sobre L. interrogans en cuyes son de tipo experimental, en los cuales esta especie se usa como biomodelo para establecer rutas de entrada, lesiones causadas en órganos blanco (hígado, riñón y pulmón) y evaluación de la respuesta inmunitaria mediante la inoculación de la bacteria a diferentes dosis(22,23). En 2020, un estudio realizado en granjas de cuyes familiares y comerciales en Cajamarca-Perú, reportó una seroprevalencia de
$40,50 \%$ de anticuerpos contra Leptospira spp. mediante la prueba de migroaglutinación (MAT), identificando los serovares Icterohaemorrhagiae 19,01\%, Canicola 16,53\%, y Pomona 8,68\%(24). Otro estudio identificó los factores asociados a seropositividad de Leptospira spp. en humanos y reportó que la tenencia de cuyes como mascotas es un factor de riesgo para la infección(25). Finalmente, en Colombia, un estudio realizado en el departamento de 
Putumayo resaltó que la susceptibilidad de los cuyes a Leptospira aumenta la posibilidad de transmisión de la enfermedad a los humanos y otras especies animales, y recomienda desarrollar investigaciones complementarias para identificar la importancia de la especie Cavia porcellus en la cadena epidemiológica de la enfermedad(26).

Una revisión sistemática sobre la prevalencia de la leptospirosis en Colombia utilizando pruebas de diagnóstico como Microaglutinación (MAT) y Enzimoinmunoanálisis de adsorción (ELISA) indica variabilidad en las diferentes poblaciones reportando que las prevalencias encontradas están entre $6 \%$ y el $35 \%$ para humanos, $41 \%$ y $60,9 \%$ para bovinos, $10,3 \%$ para porcinos, $12 \%$ y $47,14 \%$ para caninos, $23,07 \%$ para primates no humanos y entre el $25 \%$ y el $82,7 \%$ en roedores, siendo las más altas(27).

La alta prevalencia de roedores infectados juega un papel importante en la trasmisión de Leptospira a otros mamíferos, incluyendo al humano(28). Por lo tanto, debido a las características en los sistemas familiares de producción de cuyes en Nariño, en los que se resalta la ausencia de instalaciones de crianza; no existen barreras físicas que impidan el ingreso de roedores silvestres $\mathrm{u}$ otras especies de animales domésticos, permitiendo el contacto directo con los cuyes y la potencial contaminación del agua y comida con orina y heces, permitiendo la diseminación del agente en esta población( ${ }^{(9)}$. Adicionalmente, las condiciones ambientales generadas por el manejo de los animales (camas con material orgánico y alimentación en el suelo), crean ambientes cálidos y húmedos, ideales para la supervivencia de la

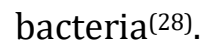

En los sistemas de crianza tanto familiares como comerciales no es frecuente el uso de elementos de protección personal en el momento de manipular los animales o el material orgánico en contacto con la orina, facilitando la exposición de las personas a la bacteria(3). De igual manera, durante el proceso de sacrificio de los cuyes se observó la ausencia de cualquier tipo de protección personal. La falta de uso de estos elementos podría explicarse por el desconocimiento de los riesgos biológicos por parte de la población y por la falta de control oficial en la aplicación de la normatividad que regula el funcionamiento de plantas de sacrificio para productos cárnicos provenientes de especies domésticas como el cuy(29). En estudios realizados en otras especies se identificó que el uso inadecuado o ausencia del equipo de protección personal para los trabajadores de los mataderos es un factor de riesgo para la exposición a Leptospira(30,31). Adicionalmente, debe mencionarse que la identificación de Leptospira en plantas de sacrificio es un excelente método de vigilancia para la enfermedad porque en la mayoría de los sistemas productivos es difícil diagnosticarla dadas las características silenciosas de la infección( ${ }^{(32) .}$

Por otro lado, hasta el momento no hay evidencia que sugiera que exista riesgo de infección por el consumo de carne de animales infectados con Leptospira. Al respecto, existen evidencias de la desintegración de las espiroquetas cuando son expuestas por períodos cortos de tiempo a temperaturas superiores a 45 ${ }^{\circ} \mathrm{C}(33,34)$, por lo cual el proceso de cocción será suficiente para disminuir el riesgo. En el caso de los cuyes, se pudo observar que dentro del proceso de sacrificio se hace uso de agua caliente a una temperatura mayor a $60{ }^{\circ} \mathrm{C}$ para facilitar el retiro del pelo, y posteriormente las vísceras son sometidas a ebullición y asado sugiriendo que el riesgo para el consumidor final es bajo. Sin embargo, para llegar a esta conclusión es importante establecer cuáles son los factores de riesgo para la infección en esta especie y en los humanos expuestos, así como las medidas de protección personal que deben implementarse durante el manejo en los sistemas de producción y los mataderos como se ha realizado con otras especies animales $(25,30,35)$.

Finalmente, es necesario recordar que la leptospirosis en humanos es mucho más frecuente de lo que se supone. Al respecto, la Organización Mundial de la Salud (OMS) refiere que en algunos países esta enfermedad no es correctamente diagnosticada y en otros, los casos no son notificados como leptospirosis, debido a la similitud de sus signos y síntomas con otras enfermedades como la malaria y el dengue $(36,37)$. En Colombia, la leptospirosis hace parte de las zoonosis de notificación obligatoria al Sistema Nacional de Vigilancia en Salud Pública (Sivigila) desde el año 2007(38). Dentro de los informes de los casos notificados al Sivigila en el período 2012-2016 se encontró que el $47,1 \%$ de los casos tuvo contacto con animales domésticos como perros y el $46,9 \%$ con ratas en el domicilio(36). En Nariño, durante el 2020 se reportó un solo caso y a la semana epidemiológica 13 del año 2021 ya se han reportado $11 \operatorname{casos}^{(39)}$. La deficiencia en la notificación de la enfermedad limita las actividades de prevención y control en la población humana, reflejado en las pérdidas socioeconómicas por las altas tasas de morbilidad y 
mortalidad, obviando las situaciones de riesgo en la interfaz humano-animal-ecosistema que convierten a la leptospirosis en una zoonosis de alto impacto en la salud pública y de preocupación a nivel mundial(40).

\section{Conclusiones}

El estudio demostró la presencia de L. interrogans en cuyes sacrificados para el consumo humano en el municipio de Pasto mediante la prueba PCR convencional $(1,5 \%, 4 / 270)$ y tinción diferencial W-S $(25 \%, 1 / 4)$. La circulación del patógeno en esta población representa un riesgo de infección para los humanos y otras especies de animales domésticos en contacto con estos sistemas de producción.

\section{Limitaciones y recomendaciones}

Los hallazgos evidencian la presencia de $L$. interrogans en las muestras evaluadas, pero no se identificaron los serovares presentes en los cuyes, lo cual permitiría conocer los vínculos epidemiológicos con otras especies.

No se pudo establecer el lugar de origen de los animales sacrificados lo que no permitió asociar las características de crianza con la positividad en las muestras.

Con la evidencia de la presencia de Leptospira en la especie Cavia porcellus, se recomienda realizar un estudio de prevalencia a nivel de granja que haga el seguimiento de los animales hasta el momento del sacrificio con el fin de identificar los factores de riesgo asociados a la infección en esta especie. También sería interesante realizar un estudio en la población de productores y personal de matadero, para establecer la asociación entre la presencia de la infección en animales y en humanos expuestos para promover la creación de programas sanitarios y de bioseguridad en los sistemas de producción y beneficio de los cuyes, y de esta forma fortalecer las políticas públicas dirigidas a mejorar el sistema de vigilancia de leptospirosis en humanos.

\section{Agradecimientos}

Los autores expresan su agradecimiento a la Universidad CES, la Escuela de Graduados y el grupo de Ciencias Básicas por el apoyo en la ejecución de las pruebas diagnósticas moleculares.

\section{Fuentes de financiación}

Este proyecto fue financiado a través de la convocatoria docente de la Vicerrectoría de
Investigaciones e Interacción Social de la Universidad de Nariño.

Conflicto de intereses: No se declaran conflictos de interés en la presente investigación.

\section{Referencias}

1. COLOMBIA - Encuesta Nacional Agropecuaria - ENA - 2016. Colombia: Departamento Administrativo Nacional de Estadística - DANE; 2016. Disponible en: https://microdatos.dane.gov.co/index.php/catalog/671/da tafile/F11/V1621

2. Secretaría de Agricultura y Desarrollo Rural. Plan departamental de extensión agropecuaria del departamento de Nariño PDEA - Nariño. San Juan de Pasto: Gobernación de Nariño; 2019. Disponible en: https://www.minagricultura.gov.co/ministerio/direcciones /Documents/PDEA\%27s\%20Aprobados/PDEA\%20Nari\%C 3\%B1o.pdf

3. Patiño Burbano RE, Cardona-Iglesias JL, Carlosama-Ojeda LD, Portillo-López PA, Moreno DC. Parámetros zootécnicos de Cavia porcellus en sistemas productivos de Nariño y Putumayo (Colombia). Ces Med Vet Zootec [Internet]. 2019 Dec;14(3):29-41. Disponible en: https://revistas.ces.edu.co/index.php/mvz/article/view/50 53

4. Caycedo A, Bastidas J, Muñoz L, Cortés M, Pérez P. El Cuy Historia, Cultura y Futuro Regional. 1 ed. Colombia: Alcaldía Municipal de Pasto; 2004.

5. Fry NK, La Ragione RM, Ready D. Leptospirosis. J Med Microbiol [Internet]. 2019 Mar;68(3):289. DOI: 10.1099/jmm.0.000899.

6. Vincent AT, Schiettekatte O, Goarant C, Neela VK, Bernet E, Thibeaux R, et al. Revisiting the taxonomy and evolution of pathogenicity of the genus Leptospira through the prism of genomics. PLoS Negl Trop Dis [Internet]. 2019 May;13(5):e0007270. DOI: 10.1371/journal.pntd.0007270.

7. Levett PN. Leptospirosis. Clin Microbiol Rev [Internet]. 2001 Apr;14(2):296-326. DOI: 10.1128/CMR.14.2.296-326.2001.

8. Bertelloni F, Cilia G, Turchi B, Pinzauti P, Cerri D, Fratini F. Epidemiology of leptospirosis in North-Central Italy: Fifteen years of serological data (2002-2016). Comp Immunol Microbiol Infect Dis [Internet]. 2019 Aug;65:14-22. DOI: 10.1016/j.cimid.2019.04.001.

9. Rodríguez Pérez R, González Gómez AI, Palacios Arias A. Leptospirosis en el entorno actual. Rev electron Zoilo [Internet]. 2014 Nov;39(12). Disponible en: http://revzoilomarinello.sld.cu/index.php/zmv/article/vie $\mathrm{w} / 127$

10. Mori M, Bourhy P, Le Guyader M, Van Esbroeck M, Djelouadji Z, Septfons A, et al. Pet rodents as possible risk for leptospirosis, Belgium and France, 2009 to 2016. Euro Surveill [Internet]. 2017 Oct;22(43). DOI: 10.2807/15607917.ES.2017.22.43.16-00792.

11. Philip N, Bahtiar Affendy N, Ramli SNA, Arif M, Raja P, Nagandran E, et al. Leptospira interrogans and Leptospira kirschneri are the dominant Leptospira species causing human leptospirosis in Central Malaysia. PLoS Negl Trop Dis [Internet]. $2020 \quad$ Mar;14(3):e0008197. DOI: 10.1371/journal.pntd.0008197.

12. Bierque E, Thibeaux R, Girault D, Soupé-Gilbert ME, Goarant C. A systematic review of Leptospira in water and soil 
environments. PLoS One [Internet]. 2020 Jan;15(1):e0227055. DOI: 10.1371/journal.pone.0227055.

13. Azhari NN, Ramli SNA, Joseph N, Philip N, Mustapha NF, Ishak $\mathrm{SN}$, et al. Molecular characterization of pathogenic Leptospira sp. in small mammals captured from the human leptospirosis suspected areas of Selangor state, Malaysia. Acta Trop [Internet]. 2018 Dec; 188:68-77. DOI: 10.1016/j.actatropica.2018.08.020.

14. Gutiérrez JD, Martínez-Vega RA, Botello H, Ruiz-Herrera FJ, Arenas-López LC, Hernandez-Tellez KD. Environmental and socioeconomic determinants of leptospirosis incidence in Colombia. Cad Saude Publica [Internet]. 2019 Mar;35(3):e00118417. DOI: 10.1590/0102-311X00118417.

15. Merien F, Portnoi D, Bourhy P, Charavay F, Berlioz-Arthaud A, Baranton G. A rapid and quantitative method for the detection of Leptospira species in human leptospirosis. FEMS Microbiol Lett. 2005 Aug;249(1):139-47. DOI: 10.1016/j.femsle.2005.06.011.

16. Peláez Sánchez RG, López Quintero JÁ, Pereira MM, AgudeloFlórez P. High-Resolution Melting Curve Analysis of the $16 \mathrm{~S}$ Ribosomal Gene to Detect and Identify Pathogenic and Saprophytic Leptospira Species in Colombian Isolates. Am J Trop Med Hyg. 2017 May;96(5):1031-8. DOI: 10.4269/ajtmh.16-0312.

17. Saitou N, Nei M. The neighbor-joining method: a new method for reconstructing phylogenetic trees. Mol Biol Evol. 1987 Jul; 4(4):406-25. DOI: 10.1093/oxfordjournals.molbev.a040454.

18. Kimura M. A simple method for estimating evolutionary rate of base substitutions through comparative studies of nucleotide sequences. J Mol Evol. 1980;16(2):111-20. DOI: 10.1007/BF01731581.

19. Tamura K, Stecher G, Peterson D, Filipski A, Kumar S. MEGA6: Molecular Evolutionary Genetics Analysis version 6.0. Mol Biol Evol. $2013 \quad$ Dec;30(12):2725-9. DOI: 10.1093/molbev/mst197.

20. Prophet EB, Mills B, Arrington JB, Sobin LH. Métodos Histotecnológicos. En: Heffess CS, Mullick FG, editores. Registro de Patología de los Estados Unidos de América (ARP) e Instituto de Patología de las Fuerzas Armadas de los Estados Unidos de América (AFIP). Washington D.C: Instituto de Patología de las Fuerzas Armadas de los Estados Unidos de América;1995.

21. Yang B, de Vries SG, Ahmed A, Visser BJ, Nagel IM, Spijker R, et al. Nucleic acid and antigen detection tests for leptospirosis. Cochrane Database Syst Rev. 2019;(8):CD011871.

DOI: 10.1002/14651858.CD011871.pub2.

22. Ajayi OL, Antia RE, Oladipo TM. Dissemination kinetics and pathology of canine Leptospira icterohaemorrhagiae isolate in a guinea pig infection model. J Immunoassay Immunochem. 2021;42(3):314-34. $10.1080 / 15321819.2020 .1863818$.

23. Lin X, Xiao G, Luo D, Kong L, Chen X, Sun D, et al. Chimeric epitope vaccine against Leptospira interrogans infection and induced specific immunity in guinea pigs. BMC Microbiol. 2016 Oct;16(1):241. DOI: 10.1186/s12866-016-0852-y.

24. Gutiérrez A, Morales-Cauti S. Determinación de anticuerpos contra serovares de Leptospira spp en cuyes de crianza familiar-comercial en Cajabamba, Perú. Rev investig vet Perú. 2020 Dec;31(4):e19043. Disponible en: https://revistasinvestigacion.unmsm.edu.pe/index.php/vet erinaria/article/view/19043

25. Brockmann SO, Ulrich L, Piechotowski I, Wagner-Wiening C, Nöckler K, Mayer-Scholl A, et al. Risk factors for human
Leptospira seropositivity in South Germany. Springerplus. 2016;5(1):1796. DOI: 10.1186/s40064-016-3483-8.

26. Romero MH, Astudillo M, Aguillón DM, Lucio ID. Evidencia serológica de leptospirosis canina en la comunidad indígena Kamentsá, Putumayo, Colombia. RIVEP. 2018 May;29(2):625-34. Disponible en: https://revistasinvestigacion.unmsm.edu.pe/index.php/vet erinaria/article/view/14495

27. Carreño Buitrago LA, Salas Botero D, Beltrán Ríos KB. Prevalencia de Leptospirosis en Colombia: revisión sistemática de literatura. Rev salud pública. 2017;19(2):2049. DOI: 10.15446/rsap.v19n2.54235.

28. Hurd J, Berke O, Poljak Z, Runge M. Spatial analysis of Leptospira infection in muskrats in Lower Saxony, Germany, and the association with human leptospirosis. Res Vet Sci. 2017;114:351-4. DOI: 10.1016/j.rvsc.2017.06.015.

29. Ministerio de Salud y Protección Social. Decreto Número 2270 de 2012. 2012. Disponible en: https://www.minsalud.gov.co/sites/rid/Lists/BibliotecaDi gital/RIDE/DE/DIJ/Decreto-2270-de-2012.pdf

30. Ngugi JN, Fèvre EM, Mgode GF, Obonyo M, Mhamphi GG, Otieno CA, et al. Seroprevalence and associated risk factors of leptospirosis in slaughter pigs; a neglected public health risk, western Kenya. BMC Vet Res. 2019 Nov;15(1):403. DOI: 10.1186/s12917-019-2159-3.

31. Benavides Benavides B, Jiménez Salas EA, Riascos Enríquez DF. Factores de riesgo asociados a la seroprevalencia de brucelosis y leptospirosis en los operarios de la planta de beneficio de Pasto, Nariño. Rev Univ Salud. 2012;14(1):42-9. Disponible

en: http://www.scielo.org.co/scielo.php?script=sci_arttext\&pid $=$ S0124-71072012000100004\&lng=es

32. Bertelloni F, Turchi B, Vattiata E, Viola P, Pardini S, Cerri D, et al. Serological survey on Leptospira infection in slaughtered swine in North-Central Italy. Epidemiol Infect. 2018 Jul;146(10):1275-80. DOI: 10.1017/S0950268818001358.

33. Parker J, Walker M. Survival of a pathogenic Leptospira serovar in response to combined in vitro $\mathrm{pH}$ and temperature stresses. Vet Microbiol. 2011;152(1-2):146-50. DOI: 10.1016/j.vetmic.2011.04.028.

34. Barragan V, Olivas S, Keim P, Pearson T. Critical Knowledge Gaps in Our Understanding of Environmental Cycling and Transmission of Leptospira spp. Appl Environ Microbiol. 2017 Sep;83(19):e01190-17. DOI: 10.1128/AEM.01190-17.

35. Calderón JC, Astudillo M, Romero MH. Caracterización epidemiológica de la infección por Leptospira spp. en caballos de trabajo y en personas ocupacionalmente expuestas en seis unidades de la Policía Nacional de Colombia. Biomédica. 2019 May;39(Suppl 1):19-34. DOI: 10.7705/biomedica.v39i1.4475.

36. Calderón-Sierra DM, Jaimes CP, Pedraza AM. Comportamiento epidemiológico de la leptospirosis humana en Colombia, 2012-2016. Rev Cuba Med Tropical. 2019;71(2):e364. Disponible en: http://www.revmedtropical.sld.cu/index.php/medtropical/ article/view/364

37. Villarreal JR, Murillo E, Ramírez-García R, Peláez-Sánchez R, López JA, Ruiz-López F, et al. Brotes emergentes de leptospirosis del Amazonas colombiano. Rev cubana Med Trop. 2019;71(1):e280. Disponible en: http://scielo.sld.cu/scielo.php?script=sci_arttext\&pid=S037 5-07602019000100011\&lng=es

38. Bello S, Rodríguez M, Paredes A, Mendivelso F, Walteros D, Rodríguez $\mathrm{F}$, et al. Comportamiento de la vigilancia 
epidemiológica de la leptospirosis humana en Colombia, 2007-2011. Biomédica. 2013 Aug;33(Suppl 1):153-60. Disponible

en: https://revistabiomedica.org/index.php/biomedica/article /view/1608

39. Consejo departamental de zoonosis. Pasto; 2021 Apr 16. Instituto Departamental de Salud de Nariño-IDSN (2021).
40. Pereira MM, Schneider MC, Munoz-Zanzi C, Costa F, Benschop J, Hartskeerl R, et al. A road map for leptospirosis research and health policies based on country needs in Latin America. Rev Panam Salud Publica. 2018 Feb;41:e131. DOI: 10.26633/RPSP.2017.131. 